\title{
Analysis of an Induction Machine by the Finite Element Method
}

\author{
Miklós KUCZMANN, Krisztián GADÓ \\ Department of Automation \\ Széchenyi István University \\ Györ, Hungary
}

kuczmann@sze.hu; gkrisztian@protonmail.com

\author{
Dániel MARCSA \\ eCon Engineering Kft. \\ Budapest, Hungary \\ daniel.marcsa@econengineering.com
}

\author{
Sándor HORVÁTH, István VAJDA \\ Kandó Kálmán Faculty of Engineering \\ Óbuda University \\ Budapest, Hungary
}

horvathsandorrajmund@gmail.com ; vajda@uni-obuda.hu

Anouar BELAHCEN

Department of Electrical Engineering and Automation

Aalto University, Finland

Anouar.Belahcen@aalto.fi

\begin{abstract}
Induction machines are popular in every segments of industry due to their simple construction and robust operation. Asynchronous machines have been being built in electric vehicles, too. The paper presents the two dimensional analysis of a voltage-fed induction machine by different kind of finite element software. The results have been compared.
\end{abstract}

Keywords-induction machine; finite element analysis

\section{INTRODUCTION}

This paper presents a comprehensive analysis of an induction machine by solving the problem by different kind of finite element (FEM) software and comparison of the results. The geometry of the motor as well as the parameters and working conditions can be found in the thesis [1]. The eddy currents in the solid steel rotor and the approximate magnetic field inside the stator core have been computed by the magnetic vector potential [2,3]. Only two dimensional simulations have been performed. The results of COMSOL Multiphysics [4], Ansys Maxwell [5] and FEMM [6] have been compared and presented. Voltages and currents of the coils and the resulting torque are shown.

\section{GEOMETRY OF THE PROBLEM}

The geometry cross-section of the analyzed four pole motor is shown in Fig. 1. Important data are presented in Table I (see [1] for details). The stator coils of the studied three phase machine are star connected $(380 \mathrm{~V}, 50 \mathrm{~Hz})$. The rated power of machine is $7.5 \mathrm{~kW}$. The slip is $5 \%$.

The laminated stator core is made of the electrical steel sheet STABOLEC 260-50A. The conductivity is assumed to be zero in $2 \mathrm{D}$ analysis. The solid steel rotor is made up of the steel Ovako $520 \mathrm{~L}$ which conductivity is $3.95 \mathrm{MS} / \mathrm{m}$ at $100^{\circ} \mathrm{C}$. The nonlinear BH curves of the stator and the rotor are shown in Fig. 2 and in Fig. 3. The stator is with 36 slots, the rotor has

The first Author is supported by the ÚNKP-17-4 New National Excellence Program of the Ministry of Human Capacities.
84 axial slits which is advantageous in terms of the torque [1].

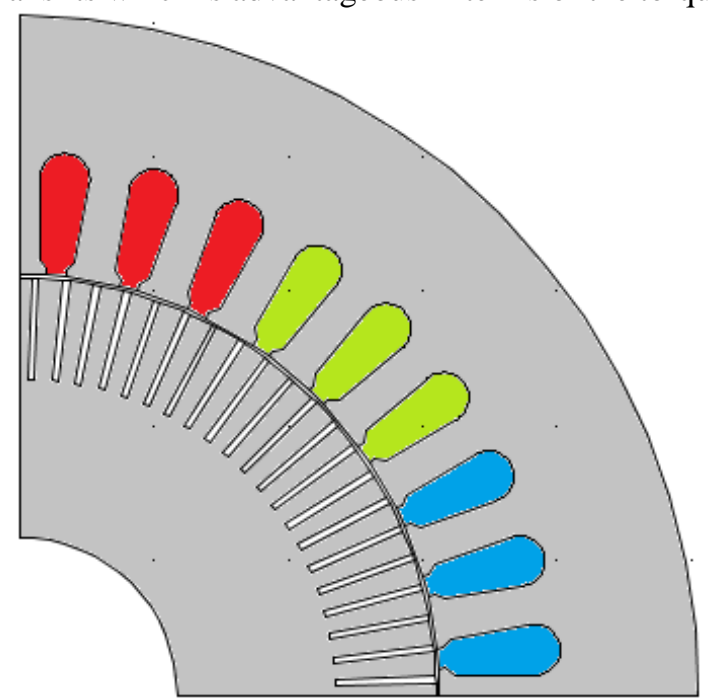

Fig. 1. The cross-section of geometry

TABLE I. MACHINE DATA

\begin{tabular}{|c|c|}
\hline Parameter & Value \\
\hline Outer diameter of stator & $202 \mathrm{~mm}$ \\
\hline Inner diameter of stator & $125 \mathrm{~mm}$ \\
\hline Outer diameter of rotor & $124 \mathrm{~mm}$ \\
\hline Inner diameter of rotor & $47 \mathrm{~mm}$ \\
\hline Effective length of machine & $146 \mathrm{~mm}$ \\
\hline Number of conductors in a stator slot & 20 \\
\hline Resistance of stator phase at $100^{\circ} \mathrm{C}$ & $696 \mathrm{~m} \Omega$ \\
\hline End-winding reactance of stator phase & $239 \mathrm{~m} \Omega$ \\
\hline
\end{tabular}


The temperature inside the machine at steady state is assumed to be $100^{\circ} \mathrm{C}$.

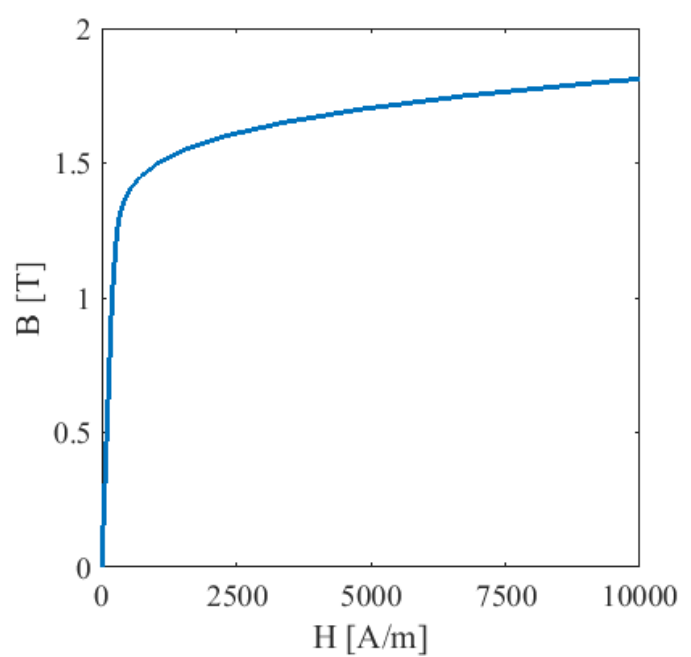

Fig. 2. The BH curve of stator material

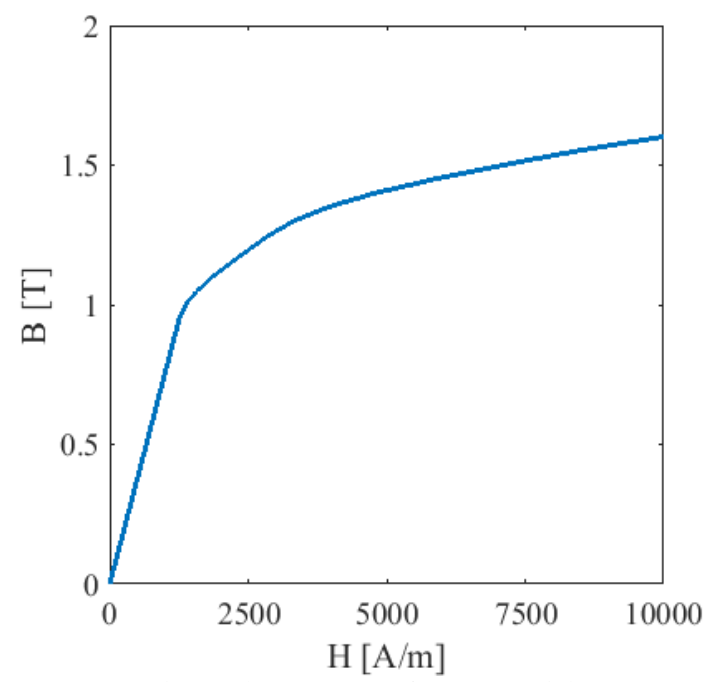

Fig. 3. The BH curve of rotor material

\section{ON THE SOLVERS}

The problem has been solved by different kind of software applying FEM. Two commercial software have been used, COMSOL Multiphysics 3.5.a. and Ansys Maxwell, furthermore a free one, called FEMM. The code FCSMEK (see a result in Fig. 4.) also has been applied in the thesis [1].

The magnetic vector potential has been applied to solve the electromagnetic field problem [2,3,7]. Only the fourth of the geometry has been discretized -by a finite element mesh containing triangular elements- due to the symmetry. Periodicity of geometry has been handled by the periodic boundary condition. The voltage-fed stator circuits with endwindings have been modelled by ordinary differential equations, but it has not been taken into account in FEMM. Only the stationary current has been set in this case. The circuits can be simulated by Spice model, too. Rotor motion has been taken into consideration by the moving mesh method [8]. The system of nonlinear equations in every time instants has been solved by the Newton-Raphson technique [3,7]. The torque has been calculated by Maxwell's stress tensor method and by the Arkkio's equation $[7,8]$. 


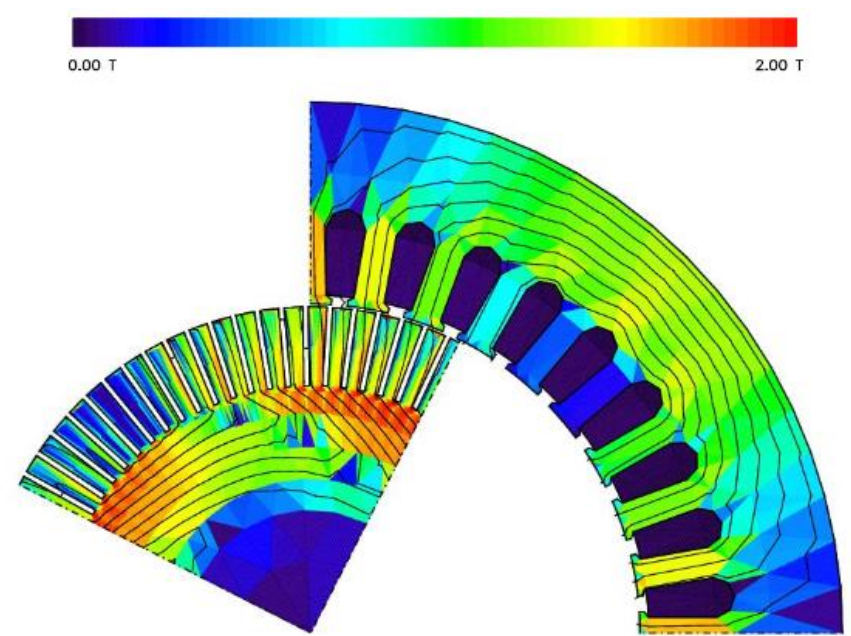

Fig. 4. The magnetic flux density by FCSMEK [1]

\section{Simulation RESUlts}

The following data have been compared (see Table II): the line current of the three phases, the voltage of coils' part in the stator slots without the end-winding region, the power factor and the resulting torque.

It is highlighted that the coil of stator has two parts in the simulations. The end-winding region is simulated by a serial connected resistor and an inductance, the other part consists of parallel wires in the stator slots modelled by FEM. The voltage of the latter part is shown in Table II.
Of course, the results of the different solvers are very close to each other's.

TABLE II. COMPARISON OF Simulated RESUlts

\begin{tabular}{|c|c|c|c|}
\hline Parameter & FCSMEK & COMSOL & ANSYS \\
\hline $\begin{array}{c}\text { Line current } \\
\text { (peak value) [A] }\end{array}$ & 20.7 & 20.9 & 20.8 \\
\hline $\begin{array}{c}\text { Coil voltage in stator } \\
\text { (peak value) [V] }\end{array}$ & n.a. & 296 & 298.7 \\
\hline Power factor, cos $\varphi$ & 0.72 & 0.66 & 0.66 \\
\hline Airgap torque [Nm] & 35.5 & 35.5 & 35.3 \\
\hline
\end{tabular}

The amplitude of voltage source has been increased asymptotically in COMSOL to decrease the effect of transients on the nonlinear solver. The coils of stators have a part in the slots as it is shown above. The voltages of these parts are presented in Fig. 5, and the line currents are given in Fig. 6.

In case of Ansys Maxwell, the line currents are shown in Fig. 7. The source voltage has turned on at the beginning, i.e. the current in the transient is very high. Fig. 8. shows the airgap torque in the transient as well as in the stationary state.

Fig. 9. shows the magnetic flux density lines simulated by FEMM where the line currents have been set as the source of electromagnetic field. The obtained torque is $36.6 \mathrm{Nm}$, which is close to the results in Table II.

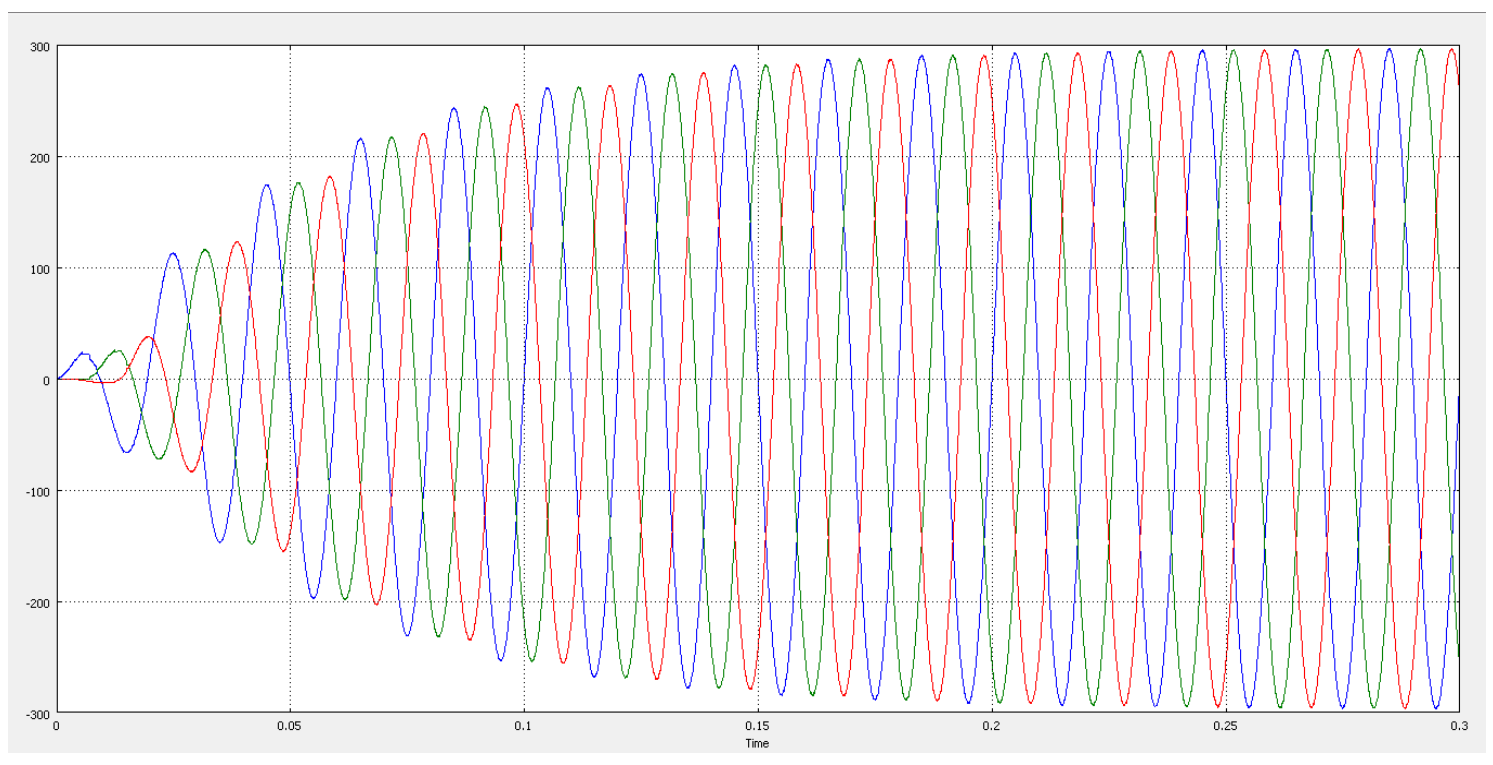

Fig. 5. Time functions of coils' voltages in the stator slots 


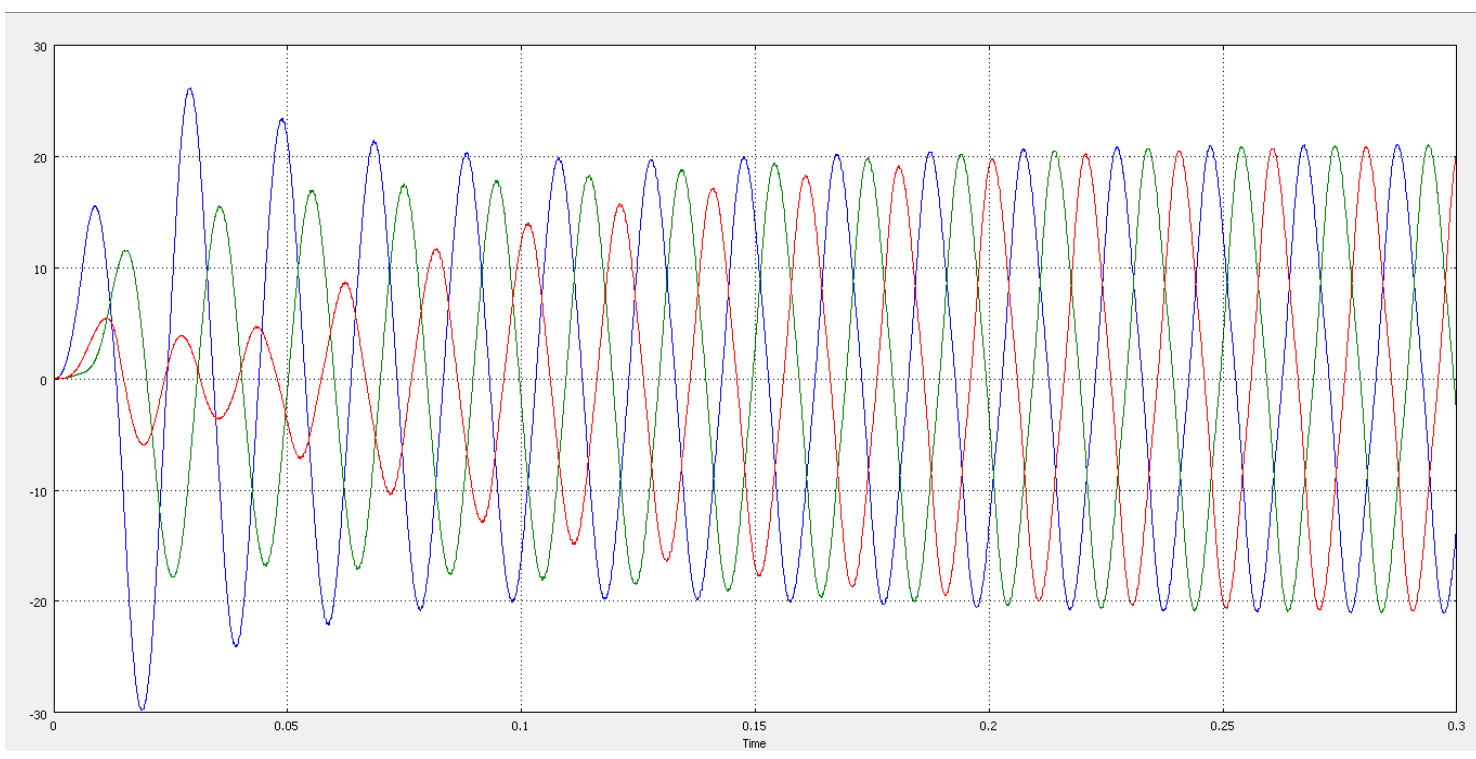

Fig. 6. Time functions of line currents by COMSOL

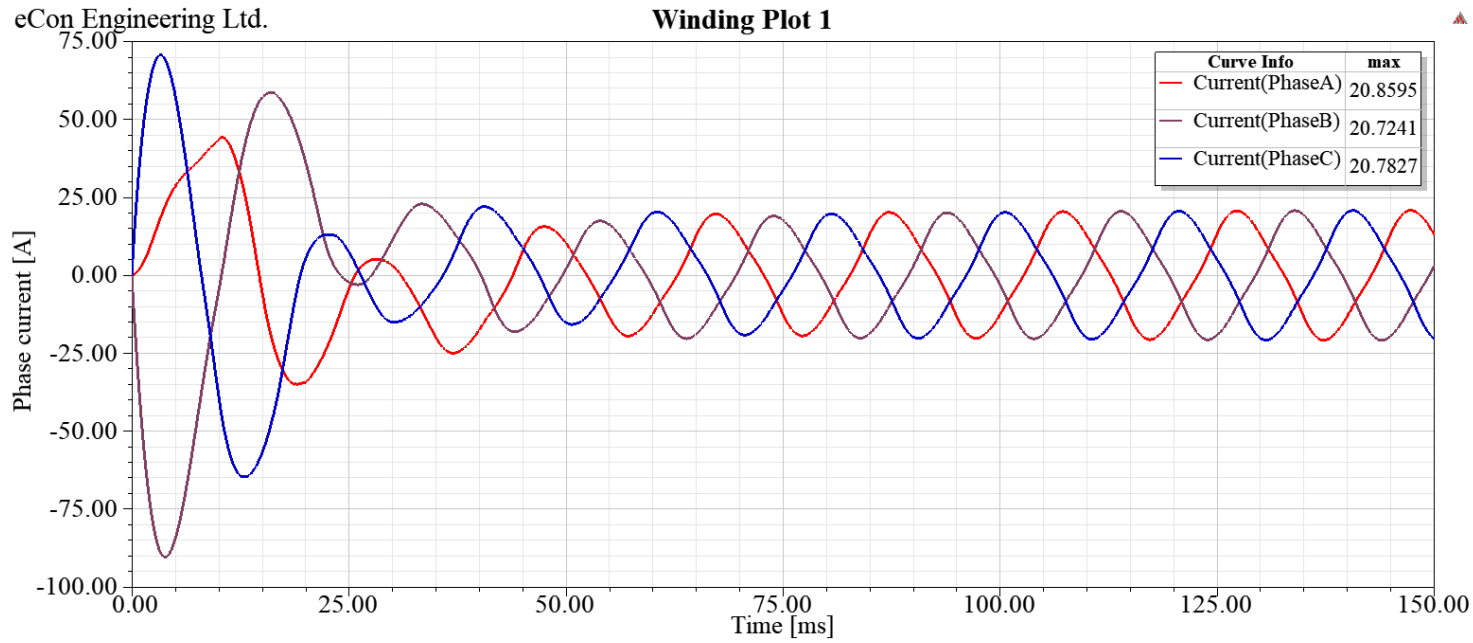

Fig. 7. Time functions of line currents by Ansys

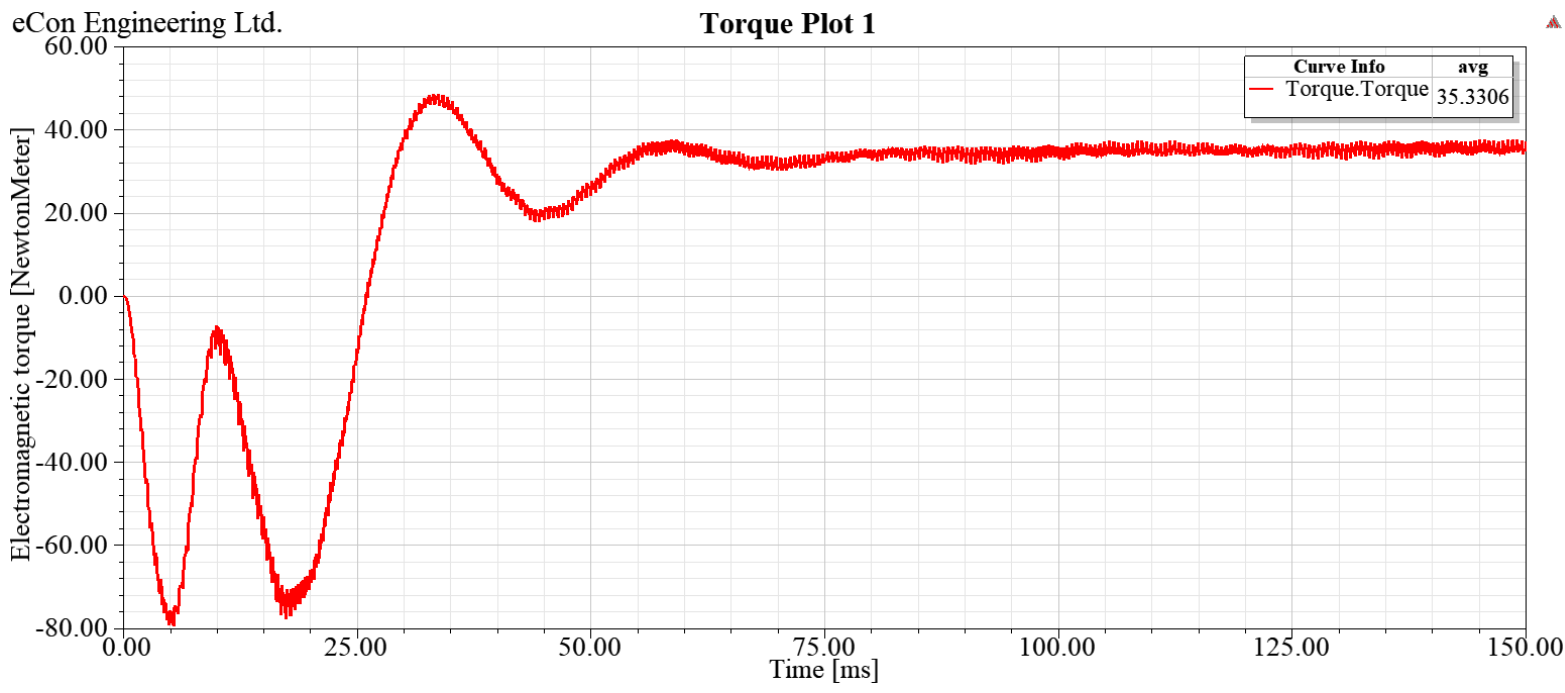

Fig. 8. Time function of airgap torque by Ansys 


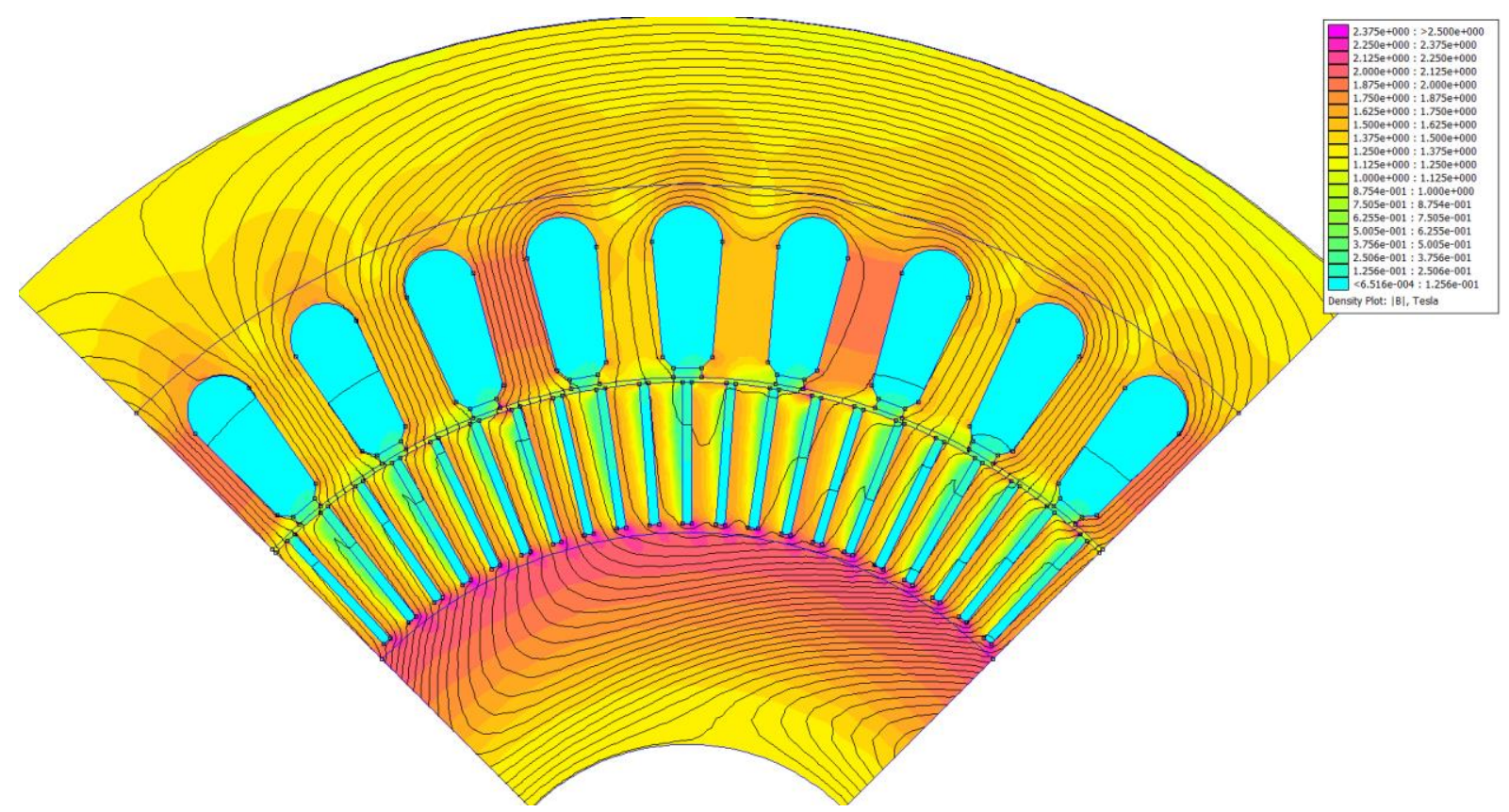

Fig. 9. Flux lines by FEMM

\section{CONCLUSIONS}

A nominal induction machine has been modelled by four different FEM based software. The results are accurate enough to use them as reference for any further investigations. Loss calculation in laminated parts is a hot topic and it is one of the open questions that must be answered in a future paper.

\section{References}

[1] B. Silwal, Computation of eddy currents in a solid rotor induction machine with 2-D and 3-D FEM, MSc Thesis, Aalto University. Helsinki, 2012.
[2] M. Kuczmann, A. Iványi, The finite element method in magnetics, Academic Press, Budapest, Hungary, 2008.

[3] J.P.A. Bastos, N. Sadowski, Magnetic materials and 3D finite element modeling, CRC Press, 2014.

[4] https://www.comsol.com/ (last visited on $18^{\text {th }}$ March 2018)

[5] https://www.ansys.com/ (last visited on $18^{\text {th }}$ March 2018)

[6] http://www.femm.info/wiki/HomePage (last visited on $18^{\text {th }}$ March 2018)

[7] A. Arkkio, Analysis of induction motors based on the numerical solution of the magnetic field and circuit equation, $\mathrm{PhD}$ dissertation, Aalto University, Helsinki, 1987.

[8] D. Marcsa, Parallel finite element methods to solve coupled electrodynamic problems, PhD dissertation, Széchenyi István University, 2017. 